\title{
Assim falava Barbie: \\ UMA BONECA PARA TODOS E PARA NINGUÉM
}

\author{
Michelle Brugnera Cruz Cechin $\star$ \\ Thaise da Silva $\star \star$
}

\begin{abstract}
Resumo
Envolta em um mundo de beleza, riqueza e aventura, a boneca Barbie está imersa em uma pedagogia cultural, com o intuito de ensinar a supremacia de um tipo de corpo, etnia e comportamento. Este artigo tem como objetivo discutir as representações da boneca Barbie na cultura lúdica e o modo como tem afetado a construção das identidades infantis, especialmente em relação à identidade de gênero e à diversidade cultural. Analisa-se o que estudos especificos têm revelado sobre as representações culturais da boneca. Para tanto, foram tomados como referencial os Estudos Culturais, tendo como marco teórico a abordagem PósEstruturalista de análise, tratando a boneca como um artefato cultural. Destacamse seus efeitos produzidos pela mídia e pela configuração discursiva da infância.

Palavras-chave: brinquedo; infância; relações de gênero; inclusão social.
\end{abstract}

\section{Thus SPOKE BARBIE: A DOLL FOR ALL AND FOR NONE}

\begin{abstract}
Shrouded in a world of beauty, wealth and adventure, the Barbie doll is immersed in a cultural pedagogy, with the intent to teach the supremacy of a body type, ethnicity and behavior. This article aims to discuss the representations of the Barbie doll in ludic culture and how it has affected the construction of children's identities, especially in relation to gender identity and to cultural diversity. It analyzes what specific studies have revealed about the cultural representations of the doll. For such, cultural studies were taken as referential, using as theoretical framework the post-structuralism analysis approach, treating the doll as a cultural artifact. We highlight their effects produced in the media and in the discourse of childhood configuration.
\end{abstract}

Keywords: toy; childhood; gender relations social inclusion.

^Especialista em Psicopedagoga pela pela Faculdade Porto-Alegrense. Pós-graduanda em Educação Especial e em Neuropsicopedagogia no Instituto Educacional do Rio Grande do Sul. Atualmente é professora de anos iniciais da rede municipal de ensino de Porto Alegre.

E-mail:mibrugnera@gmail.com

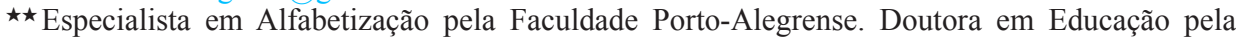
Universidade Federal do Rio Grande do Sul. Professora do curso de pós-graduação no Instituto Educacional do Rio Grande do Sul e da rede municipal de ensino de Porto Alegre.

E-mail: thaiseds@ibest.com.br 


\section{Assim Falava Barbie}

Na obra Assim Falava Zaratustra: um livro para todos e para ninguém (2011), Nietzsche utiliza o personagem-conceito Zaratustra, um lendário sábio persa, para questionar e criticar a religião, a moral e a tradição filosófica do ocidente. Para empreender a escrita deste trabalho, utilizo a boneca-personagem Barbie para criticar, questionar, problematizar a cultura voltada para a infância contemporânea junto às crianças. Critica-se a cultura inventada pelos adultos para aumentar a lucratividade por meio da venda de brinquedos, ensinando a supremacia de um tipo de corpo, raça e comportamento aos infantis.

No presente trabalho problematiza-se os modos como as imagens femininas e a pluralidade cultural são produzidas pelas grandes corporações de brinquedos, focalizando a boneca Barbie. Discute-se o modo como essas imagens estereotipadas produzem subjetividades infantis, analisando os discursos, as narrativas e as visões de um grupo de crianças dos anos iniciais do ensino fundamental

A boneca manequim mais famosa do mundo, Barbie, envolta em um mundo cor-de-rosa, que evoca magia e fantasia, pode parecer apenas um simples e inocente brinquedo para entreter e divertir crianças. No entanto, ao se revisitar sua história, emergência e permanência no mercado de brinquedos, vê-se que sua produção está imersa em intenções pedagógicas, com o intuito de ensinar a supremacia de um tipo de corpo, raça e comportamento (BROUGËRE, 2004; DEBOUZY, 1996; ROVERI, 2008; STEINBERG, 2001). Estima-se que, desde a sua criação, um bilhão de bonecas Barbies foram vendidas em mais de 150 países (LORD, 2004). Com o status de boneca mais vendida do mundo, seu sucesso é sempre vinculado à beleza, à juventude e ao consumo. Devido às diversas adaptações visuais, à representação de diferentes etnias e ao discurso multiculturalista e "inclusivo", a boneca norte-americana acompanhou as mudanças de tendência em moda, beleza e comportamento e construiu uma memória da cultura ocidental (LORD, 2004; ROVERI, 2008). Nos seus mais de 50 anos de existência, a fabricante da Barbie, a Mattel, cria inúmeros artefatos midiáticos, utensílios, roupas, acessórios, cenários e a representação das diferenças com o intuito de aumentar as vendas da boneca, fomentando a cultura do consumo (BROUGÈRE, 2004; DEBOUZY, 1996; ROVERI, 2008; STEINBERG, 2001).

Apenas um modelo de corpo, considerado normal, é representado pelas bonecas ofertadas pelo comércio atualmente. A hegemonia de um modo de ser, de uma infância considerada ideal é reproduzida nas bonecas e brinquedos mesmo com o avanço nas problematizações da pluralidade cultural e inclusão social difundidos nos meios legislativos, acadêmicos e midiáticos. Articular educação inclusiva e a diversidade no cotidiano escolar é um desafio, pois pressupõe a compreensão da alteridade. Para isso, é necessário desfazer as tramas da exclusão e abrir espaço para as múltiplas formas de ser sujeito dentro de uma cultura e um tempo histórico. Como valorizar, compreender, conviver com a diversidade se apenas uma forma de aprender, ser e estar no mundo é valorizada? 
A disciplina A fundamentação teórica é tecida nos Estudos Culturais, por se tratar de um estudo teórico, busca entender como os discursos e representações sobre as identidades infantis são constituídos culturalmente e as formas com que são representadas nos brinquedos, em especial, a boneca Barbie.

Fundamenta-se também na obra do filósofo francês Michel Foucault e de suas produções sobre os conceitos de subjetivação, saber e relações de poder, articulados ao conceito de "dispositivo" (FOUCAULT, 1993, 1996, 1998, 1999). Busca-se discutir de que maneira um dispositivo pedagógico das bonecas é organizado midiaticamente de forma a produzir modos de subjetivação infantil. Mais especificamente: o objetivo é analisar de que maneira o dispositivo pedagógico das princesas se ocupa da produção discursiva de feminilidade. Pretende-se, prioritariamente, descrever como se movimentam a produção de subjetividades e os desvios feitos pelas crianças através das brincadeiras com essas bonecas. Ou seja, interessa mostrar como sujeitos transformam-se através das brincadeiras.

Pretende-se problematizar o conceito de "dispositivo pedagógico das bonecas", concebidas e pensadas com base nos conceitos de "dispositivo de sexualidade" e de "modos de subjetivação", de Michel Foucault. Com fundamentação em tal referencial, mostra-se de que modo opera a mídia dos brinquedos na constituição de sujeitos e subjetividades na sociedade contemporânea, na medida em que produz imagens, significações e saberes que se dirigem à "educação" dos infantis, ensinando-lhes modos de ser e estar na cultura em que vivem.Propõese a análise discursiva do objeto boneca, dos enunciados de certos regimes de verdade, produzidos, veiculados e recebidos de formas muito específicas, que falam de determinados modos de existência, de modos de enunciação, de práticas de linguagem, de celebração de certas verdades tornadas hegemônicas. Ensina Foucault que o grande exercício do pensamento é a aceitação do pensar de uma forma distinta daquela a que estamos acostumados.

\section{O disPositivo PEDAGógICO DA BONECA BARBIE}

O brinquedo participa da construção da infância por meio de complexos significados e práticas produzidas não apenas por seus criadores e difusores, mas por aqueles que o utilizam. É possível entender o lugar da criança na sociedade através dos usos e significados atribuídos aos brinquedos. Por serem portadores de significados e valores culturais que revelam os discursos, concepções e representações da sociedade, revelam os conceitos de infância construídos historicamente pela cultura ocidental (BROUGÈRE, 2004). A cada momento histórico, forjam-se subjetividades próprias, pertencentes à cultura hegemônica consolidada.

Tendo em vista que as identidades infantis e suas representações são produzidas pelos discursos que se enunciam sobre ela, as representações sociais da infância são moldadas na e pela linguagem. A "virada linguística" concebe a linguagem como constituidora, em outras palavras: a linguagem forma sistematicamente os objetos sobre os quais narra. A cada época histórica forjam-se modelos hegemônicos, e certas narrativas são tidas como verdadeiras. As narrativas agora passam a ser vistas como formadoras do sujeito e, de acordo com Larrosa (1996), elas produ- 
zem as identidades, partindo-se da ideia de que somos o que contamos e o que nos contam, sob a influência dos lugares, tempo e vozes que narram, fazendo com que a narrativa se torne responsável pela formulação dos processos identitários. Com a virada linguística, a verdade única deixa de existir, sendo substituída por verdades constituídas. Estas, a partir de então, são consideradas crenças, tendo como alvo de análise o processo pelo qual algo se torna verdade (SILVA, 2007). Foucault (1993) explica que a linguagem e, consequentemente, os discursos não funcionam imunes aos controles sociais porque são atravessados pelas relações de poder.

Cada sociedade tem seu regime de verdade, sua política geral, de verdade: isto é, os tipos de discurso que aceita e faz funcionar como verdadeiros; os mecanismos e instâncias que permitem distinguir entre sentenças verdadeiras e falsas, os meios pelos quais cada um deles é sancionado. (FOUCAULT, 1993, p. 12)

$\mathrm{Na}$ crescente profusão de imagens nas quais as crianças estão imersas, determinados modos de pensar, agir e ser são ensinados e reconhecidos como legítimos. A educação imagética está cada vez mais presente na vida cotidiana dos infantis, tornando-se um âmbito legítimo da educação das subjetividades, pois a formação da identidade perpassa diversos dispositivos e personalidades culturais. As representações culturais envolvidas nas imagens pictóricas estão apenas relacionadas a uma personalidade reconhecida conscientemente dentro da cultura e com as marcas do lugar desta identidade na cultura. Dessa forma, as subjetividades são atravessadas por modelos identitários difundidos pelas imagens estampadas em filmes, brinquedos, roupas, revistas etc.

Alguns personagens veiculados pela mídia são divulgados como autoridades na autorregulação dos indivíduos. Nos discursos vinculados à Barbie, os modos de ser menina são apreendidos como objeto passível de regulação, intervenção e governamento. As narrativas dessa boneca tornaram-na uma expert da feminilidade, um modelo de corpo, conduta, beleza, estilo e um modo de empreender cuidado sobre si.

Barbie foi criada no contexto pós-guerra, uma época que possibilitou o aumento do consumismo capitalista, e o imaginário burguês foi levado às camadas populares através de diferentes ícones. É a principal representante da modalidade de bonecas manequim (BROUGÉRE, 2004; DEBOUZY, 1996; MITCHELL; REID-WALSH, 2007), que incentivam outro tipo de brincadeira. O objetivo não é cuidar e alimentar a criança-boneca, mas ser a boneca adulta. Inicialmente, eram feitas de porcelana, corpo de tecido e utilizavam roupas com modelagem da moda. Posteriormente, foram elaboradas em papel e acompanhavam os encartes das revistas de moda da época.

Barbie tem descendência alemã da boneca Lilli, que serviu de modelo para sua criação. Lilli fora criada em 1950, inspirada na personagem de quadrinhos do jornal Bild Zeitung (BROUGÈRE, 2004; GERBER, 2009; LORD, 2004; STONE, 2010). Era voltada para o público adulto, pois sua representação nas histórias ti- 
nha uma conotação pornográfica. A personagem costumava perseguir homens ricos em busca de dinheiro e sucesso. Com a produção da personagem em boneca, Lilli tornou-se um objeto icônico para os homens adultos, vendida em bares e tabacarias. Lilli não era direcionada para crianças; contudo, as crianças se apossaram dela.

Ruth Handler e Elliot Handler foram os fundadores da empresa de brinquedos Mattel, que fabrica a Barbie. Ruth Handler, ao observar sua filha Bárbara brincando, viu que ela interessava-se mais por suas bonecas de papel, pois estas tinham o corpo de uma mulher adulta e possuíam uma grande variedade de roupas que podiam ser trocadas (BROUGERE, 2004; LORD, 2004). Em 1956, o casal passava as férias com a família na Suíça quando Ruth, fazendo compras com sua filha, viu uma boneca que não conhecia. A menina quis comprá-la para enfeitar seu quarto, e a mãe levou duas bonecas para a filha e uma para entregar aos executivos da Mattel, pois havia vislumbrado a possibilidade de fabricar uma boneca com corpo adulto, como há anos desejava criar.

Inspirada no interesse de sua filha, Ruth deu inicio ao processo de criação das formas do corpo e do rosto da boneca Barbie, que durou três anos. Serviram como inspiração para o visual da boneca atrizes famosas da época, como Grace Kelly, Marilyn Monroe, Brigitte Bardot. A produção da época exigia maquiagem forte, sombras prateadas e muito delineador, unhas e batom vermelhos, corpo curvilíneo e pele pálida, tal qual as atrizes do período (LORD, 2004; ROGERS, 1999).

Ela foi lançada oficialmente na Feira Anual de Brinquedos de Nova Iorque, em 9 de março de 1959. Com trinta centímetros de altura, dois centímetros de cintura, braços rígidos e articulados, cabelos de náilon, vestindo maiô de listras pretas e brancas, salto alto e maquiagem, era uma top model. A Mattel chamou Barbie de "Modelo de Moda Adolescente" na tentativa de amenizar seu visual sensual e acentuar a ideia de que as meninas desejavam se parecer e se vestir como as modelos (GERBER, 1999).

Naquele mesmo mês, Barbie estreou na televisão, não como uma boneca mas como uma adolescente que nadava, dançava, ia a festas e trocava muitas vezes de roupa. Em seu primeiro comercial, Barbie aparece sob luzes intensas diante das câmeras com o intuito de tornar sua imagem glamorosa, ao embalo da canção que dizia: "Um dia serei como você, até lá sei o que vou fazer [...] Barbie, linda Barbie, vou fingir que sou você" (GERBER, 1999).

Ruth e Eliot venderam 34 mil bonecas desse primeiro exemplar (LORD, 2004). A boneca fez grande sucesso entre as crianças; porém, as famílias americanas conservadoras não aprovaram a boneca por sua dimensão sexy. Sua maior inovação foi a possibilidade de as garotas poderem possuir apenas uma boneca, já que estas podiam ter diversas "roupas" (STEINBERG, 2004). Conforme Brougère (2004), a inovação da Barbie não estava no objeto em si, mas na concepção de um brinquedo novo, que se inscreveu mais precisamente em uma nova ordem lúdica. A partir do objeto boneca, foi construída uma personalidade, tramada progressivamente através da narração que se fazia sobre ela. "O fabricante não vendia mais um objeto, e sim uma personalidade, uma história, um sonho" (BROUGÈRE, 2004, p.100). Pode-se dizer que a boneca Barbie é um objeto com 
identidade cultural, pois seu sucesso pode ser atribuído também às narrativas tramadas a seu respeito em diferentes mídias, que construíram e renovaram suas diversas identidades, adequando-as à cultura de cada época.

Encaminhar as meninas ao mundo imaginário da boneca é a principal publicidade da Barbie (BROUGÈRE, 2004; ROVERI, 2008; STEINBERG, 2001). Imersa em um mundo cor-de-rosa, repleta de acessórios da moda e objetos de prestígio, a menina consumidora é convencida de tê-los em sua coleção. A sua marca cor-de-rosa ensina e produz certas formas de pensar, agir, estar e se relacionar com o mundo. Desde sua primeira versão, Barbie ensina o "autogoverno", no sentido dado por Foucault (1993), um modo de cuidar de si ditado por seu estilo de vida fashion. A constituição das subjetividades contemporâneas está cercada por mecanismos de normalização através de diferentes instrumentos midiáticos que apresentam modos de ser. Dentre esses modos estão a mídia, os brinquedos, as bonecas e a Barbie, que mostram modos de ser menina.

As subjetividades são constituídas por meio do sentimento de pertença, de participação. Na publicidade da Barbie, sua mutação constante é um mecanismo de disciplinar, de governar as subjetividades femininas. Ao mesmo tempo em que mostra roupa, consumo, glamour, ela vigia o comportamento infantil com um olhar panóptico, ditando um modo de ser hegemônico. No incansável mundo de novidades e trocas de roupa da boneca, a menina é levada a acreditar que precisa constantemente trocar de roupas, adquirir novos acessórios, novas roupas e novas bonecas para se sentir pertencente.

Os estudos sobre governo, na perspectiva foucaultiana, preocupam-se em analisar procedimentos, táticas e estratégias usadas para exercer o controle da conduta (FOUCAULT, 1993). O autogoverno diz respeito aos modos de os indivíduos conduzirem-se a si mesmos, envolvendo alguma forma de controle e direcionamento ou modelo apresentado por diversos mecanismos políticos (FOUCAULT, 1993). Tal conceito torna possível a análise dos discursos das autoridades sociais e midiáticas que procuram operar sobre a vida dos indivíduos. Dessa forma, desloca-se o foco de análise: do poder do Estado para as múltiplas estratégias de controle da conduta presentes na cultura atual.

Barbie ensina que as crianças devem se dedicar à busca da felicidade por intermédio da aquisição de bens materiais. Sua pedagogia de consumo dá diversas lições sobre como adquirir bens que deem status de riqueza, acompanhar as tendências da moda e ter um estilo de vida "divertido". "Car avant tout, c'est par le vêtement que l'on devient quelqu'un (et surtout quelqu'une) et que l'on est 'popular', concept fondamental de la vie sociale des années 1950. Com esses objetivos, a roupa se torna central, pois faz com que você seja alguém especial e "popular" - um conceito fundamental da vida social na década de 1950" (DEBOUZY, 1996). Vestida por estilistas famosos como Calvin Klein e designers de sapatos como Christian Louboutin, o "guarda-roupa" versátil da Barbie opera no permanente jogo de novidade e renovação apresentado pela indústria da moda. Suas diferentes vestimentas fomentam a necessidade de consumo. 
Ao representar diferentes profissões, artistas de cinema, personagens de filmes e seriados, Barbie evoca o prazer da aparência, um sentimento narcisista de se transformar através do "visual". Seu slogam "Seja tudo o que você quiser: Barbie girl!" ensina que as meninas podem ser "livres" para ser o que quiserem através da moda e dos cuidados com a aparência (ROGERS, 1999; ROVERI, 2008).

\section{BARBIE QUEER: ENTRE CORAÇÕES FELIZES E AMIZADES COLORIDAS}

Durante quase três décadas, Barbie governou sobre o comportamento esperado das meninas e mulheres, sendo um modelo dos modos de se vestir, maquiar, cuidar do corpo. No entanto, ela também personifica um modelo feminino independente (GERBER, 2009; RAND; 2003; ROGERS, 1999). Apesar da Mattel ter criado Ken e narrar seu namoro através de diferentes mídias, Barbie não se casou e não constitutiu uma família nos moldes tradicionais.

Ken foi lançado em 1961, após dois anos do lançamento da Barbie na Feira de Brinquedos de Nova Iorque, em 1959, sendo relegado à acessório (BROUGÈRE, 2004). Sua primeira versão estava vestida com roupas de banho, e uma série de acessórios e roupas vendidas separadamente foram criadas para complementar a brincadeira. Assim como "sua namorada", teve muitas versões acompanhando as mudanças da boneca e sua educação para o consumo e comportamento jovem. Um bom exemplo da personalidade de Ken pode ser localizado no terceiro filme da saga Toy Story, produzido pela Disney-Pixar, em 2010. Apesar de afirmar veementemente que "não é um brinquedo de menina", Ken possui muitas coisas, entre elas a "casa dos sonhos" e um vasto figurino, mostrando-se vaidoso e fútil através de suas falas: "ser o Ken é ter uma vida divertida!", "O Ken tem bons genes, que ficam lindos dentro de um jeans".

Ken é um boneco controverso, pois algumas das suas versões causaram polêmica, como o Earring Magic Ken. Ele foi o primeiro boneco a ser representado com brinco, cabelos pintados com "mechas" e estava vestido com uma camiseta e colete roxos. Muitos consumidores interpretaram o visual do boneco como a representação estereotipada de um homem homossexual, causando grande venda do boneco; porém, muitas críticas à Mattel, que o recolheu das lojas (AUGUSTYNIAK, 2010; LORD, 2004).

O boneco se tornava um ícone gay com o surgimento do Earring Magic Ken, em 1993. O brinquedo era uma resposta aos pedidos das crianças por um Ken mais moderno, mas a camisa rocha e colada, o brinco de brilhante e os sapatos pretos de amarrar continham mais que um apelo centrado na demanda infantil. Para a comunidade gay ainda discriminada e relativamente escondida, havia a afirmação de que o boneco Ken podia ser tanto heterossexual como homossexual. (GERBER, 2009, p. 251) 
A palavra "boneca" é empregada em brinquedos feitos para meninas. No lugar da palavra "boneco", os fabricantes usam o termo figuras de ação, que define os personagens como velozes, maldosos, heróis e viris vendidos aos meninos (BROUGËRE, 2004; ROVERI, 2008).

Connell (2005) descreve um conceito de masculinidade que prevalece na cultura ocidental: a masculinidade hegemônica, inclinada aos esportes, à competição, às ciências exatas, à racionalidade e à identidade heterossexual. As demais representações da masculinidade, como sensível, artística, homossexual ou bissexual, são chamadas de masculinidades subalternas por estarem em patamares inferiores de poder em relação às formas hegemônicas de masculinidade, sendo alvos de exclusão, violência e ridicularização. Os bonecos contemporâneos parecem representar bem tal distinção, já que o Max Steel representa os ideais da masculinidade hegemônica, enquanto Ken é um mero acessório.

As estratégias de marketing dividem os brinquedos próprios para os meninos dos brinquedos voltados para as meninas, além das diferenças etárias, e pretendem ensinar as crianças a enxergar com naturalidade essa separação. Meninas e meninos são enquadrados em distintos segmentos do mercado, a fabricação e a exposição dos brinquedos são realizadas de modo a fixar uma identidade de gênero.Os brinquedos da contemporaneidade vêm de fábrica imbuídos de normas que definem o que é permitido e o que não é permitido para cada gênero, há um abismo que separa os "brinquedos de guerra" destinados aos garotos, dos outros "brinquedos sensíveis", exclusivos das meninas (ROVERI, 2008; ZEGAI, 2007). A lógica que preside o mundo dos brinquedos dos meninos é diferente daquela dos brinquedos produzidos para as meninas. As cores escolhidas pela publicidade para estampar as embalagens geralmente são mais escuras, os rostos com traços agressivos demonstram poder e seus membros são articulados para realizar inúmeros movimentos que simulam coragem e ousadia.

Os papéis de gênero tradicionais foram relegados aos seus amigos e vizinhos da Barbie (LORD, 2004; ROGERS, 1999). Depois do sucesso dos bonecos da coleção Família Sunshine, na década de 1970, a Mattel decidiu produzir outra linha semelhante, porém com as características da boneca Barbie. Foi assim que criaram a Heart Family, em 1980. Pela primeira vez é lançada uma boneca grávida e um casal idoso pela fabricante. Como Barbie não poderia deixar o seu papel de solteira, a Heart Family era composta por seus vizinhos: Heart Dad (papai coração), Heart Mom (mamãe coração), Heart Baby Megan (bebê coração Megan), Heart Baby Boy (bebê coração menino), New Heart (novo coração), Heart Grandmother (avó coração), Heart Grandfather (avô coração). Nessa coleção os casais eram vendidos em conjunto (LORD, 2004).

Em 1991, a melhor amiga de Barbie, Midge, casa-se com Alan. É vendido um conjunto de bonecos do casamento composto pela noiva Midge, pelo noivo Alan, Barbie e Ken como padrinhos do casamento e os irmão gêmeos de Barbie, Tutti e Todd, como aia e pajem. Uma década mais tarde é lançada a Happy Family, uma coleção composta pela família de Midge, que incluía a Midge grávida do seu segundo filho, Allan e o filho Ryan, a avó, o avô e os vizinhos. Nessa edição, 
as bonecas eram vendidas separadamente, o que acarretou em uma polêmina nos estados Unidos e a boneca foi retirada das prateleiras da Wall Mart, uma das maiores redes de lojas varejistas do país (AUGUSTYNIAK, 2010; LORD, 2004). Mesmo entre a Família Coração e a Família Feliz, Barbie permanece solteira, trocou de namorado em 2004, voltou para Ken em 2011 e continua personalizando uma feminilidade fora dos padrões tradicionais.

Alguns pesquisadores (GERBER, 2009; RAND; 2003; ROGERS, 1999) afirmam que Barbie não representa um modelo heterossexual, mas que possui um currículo queer. Barbie também foi revista sob o olhar da teoria queer, que fala de uma sexualidade transgressiva, não normatizada. Mesmo com seu visual "ultrafeminino", Barbie representaria a imagem de uma drag queen, com suas longas pernas, roupas purpurinadas, maquiagem colorida, tiaras brilhantes e inúmeros acessórios. Na década de 1990, Barbie e Ken passaram a ser ícones de lésbicas e homossexuais como, por exemplo o Earing Magic Ken. Segundo Rand (2003), o mundo da Barbie é bissexual, já que ela possui um duradouro relacionamento com Ken e com sua melhor amiga Midge. A revista de colecionador Barbie Bazaar, destinada aos adultos, possui artigos que tratam da controversa sexualidade de Barbie (RAND, 2003). Diversos colecionadores que se afirmavam como gays e lésbicas escreviam para a revista relatando sua identificação com as personalidades de Ken e Barbie. Muitas drag queens citavam a influência da Barbie em suas vidas.

\section{UMA DIVA PARA TODAS GOVERNAR}

Em meados da década de 1960, enquanto as diferenças, a pluralidade cultural e a inclusão social são temáticas que se tornaram centrais no panorama educativo nos últimos anos, a fabricante da boneca Barbie percebeu que o discurso da diversidade tinha grande potencial de marketing. Para a Mattel, diversidade consiste em tons de pele, países, línguas e hábitos alimentares diferentes dos da Barbie loura e branca. A pluralidade cultural foi relegada às amigas da Barbie, pois nada poderia retirar a supremacia da branca da boneca (ROVERI, 2008).

Lord (2004) afirma que o brinquedo é parte da indústria de entretenimento e que por isso também segue tendências. A partir da década de 1970, a indústria cinematográfica começa a produzir mais filmes com personagens negros e a indústria de brinquedos investe na representação de afro-americanos nas bonecas, pois percebe o sucesso do merchandising multicultural. Contudo, passados mais de 50 anos da sua criação, Barbie continua preponderantemente magra, branca, com cabelos loiros, compridos e lisos. As marcas inscritas na representação corporal da Barbie mostram os ideais de beleza dos séculos XX e XXI, ensinando sobre o corpo ideal (ROVERI, 2008; SOUZA, 2009; STEINBERG, 2001). Barbie apresenta uma significação corporal feminina construída sob os moldes higienistas e eurocêntricos, educando para um tipo de beleza considerada hegemônica.

Steinberg (2001) diz que a Barbie loira é o padrão a partir da qual as outras surgem. Apenas nas amigas da Barbie e em suas edições para colecionadores é que encontramos maior diversidade fenotípica. A primeira amiga negra da Barbie foi Christie, criada em 1968. Ao longo dos anos, muitas ou- 
tras amigas negras foram produzidas; contudo, elas apresentam as mesmas características da Barbie branca. A primeira Barbie negra foi lançada apenas em 1980, inscrita nos mesmos padrões norte-americanos de beleza e comportamentos juvenis legitimados em nossa cultura.

$\mathrm{Na}$ década de 1960, o movimento afro-americano e outros segmentos das minorias da sociedade americana passaram a questionar as imagens negativas das pessoas negras apresentadas por diferentes artefatos culturais. Diversas corporações passaram a revisar suas imagens publicitárias, entre elas a Mattel, que em 1967 lançou Francie, a primeira amiga negra da Barbie (SCHWARZ, 2006).

Em 1980, a primeira Barbie negra foi lançada, apresentando cabelos crespos, em estilo afro. Neste contexto, novas bonecas negras e hispânicas foram introduzidas no mercado pela Mattel, pois as populações negra, hispânica e outros grupos étnicos aumentavam nos Estados Unidos. O grande potencial de vendas das bonecas étnicas fez com que a empresa lançasse também Teresa, a amiga latino-americana da Barbie, e Kira, a amiga asiática (SCHWARZ, 2006).

Em 1991, a Mattel legitimou esse mercado lançando três bonecas negras de tons diferentes de pele, o que acarretou no aumento das vendas e na abertura de um caminho promissor para as bonecas afro-americanas produzidas há mais tempo pelas outras empresas. As três bonecas da Mattel, Shani, Asha e Nichelle, eram descritas pela fabricante "esculpidas realisticamente dos pés a cabeça para refletir a beleza natural da mulher afro-americana" (ROGERS, 1999, ROVERI, 2008). Porém, não foi criado um novo padrão de corpo para essas bonecas, os corpos da "Barbie-padrão" foram meramente pintados de negro. Segundo Roveri (2009), as descrições da fabricante sobre Shani mostram que a boneca é jovem, bonita e vivaz, sabe o que ela quer e tem autoconfiança para ir atrás de seus ideais; Shani não é apenas um belo rosto, ela é luz e escuridão.

A Mattel passou a explorar mais o marketing multicultural através da linha Bonecas do Mundo. Nesta série de bonecas Barbie, a publicidade voltouse não apenas para as meninas, como também para os adultos colecionadores, representando diferentes culturas através de supostos trajes típicos. Por exemplo, a Barbie Brasileira era morena, representada em roupas de carnaval. O Brasil também foi "homenageado" com as bonecas Carmen Miranda e Barbie Amazônia, que retraram a "riqueza cultural de nosso povo" e as "maravilhas da floresta Amazônia” (AUGUSTYNIAK, 2010).

As diferenças culturais descritas pela Mattel através da coleção Bonecas do Mundo reforçam estereótipos étnicos, principalmente através das roupas e acessórios, supostamente usados pelas mulheres de diferentes nacionalidades. No caso da boneca brasileira, a exposição do corpo, as vestes de carnaval, o tom de pele moreno e os cabelos cacheados remetendo às características da mulher mulata brasileira, além da menção à alegria do carnaval do Rio de Janeiro são características que marcam as duas versões da boneca. Apesar da pretensa plasticidade democrática de representar a diversidade cultural e étnica, a Mattel perpetua os padrões hegemônicos de beleza, pois, qualquer que seja a etnia representada, Barbie sempre estará magra, na ponta dos pés, com seios grandes. Barbie nunca 
foi representada obesa, idosa, grávida, portadora de necessidades especiais. Essas diferenças são relegadas às "outras" bonecas do "Universo Barbie". Um exemplo é o casal idoso, pais da boneca Midge, amiga grávida da Barbie. Apesar dos cabelos brancos, das rugas e das roupas, esses bonecos apresentam corpos com o mesmo padrão de beleza difundido pela Barbie (DORNELLES, 2003).

Em nenhuma das coleções da cultura mundial Barbie foi representada como mulçumana. Em 2003, a companhia Síria Newboy Design Studio introduziu uma nova, controversa e popular boneca. Ela tinha a aparência e estilo muito parecidos com os da Barbie, cabelos e olhos castanhos, usa lenço preto na cabeça e roupas tradicionais da religião muçulmana, seu nome era Fulla. Terrenée (2008) explica que Fulla é uma versão mais modesta da Barbie, ela representa uma mulher criada nos costumes muçulmanos, que respeita as tradições, é caridosa e ama seus amigos e familiares. Ela possui profissões respeitáveis, como professora e médica, e frequentemente é representada rezando, cozinhando e lendo. Assim como a Barbie, Fulla apresenta comportamento e costumes de uma cultura dominante.

Becky, a amiga tetraplégica da Barbie, lançada em 1996, era uma estudante de fotografia, participou das paraolimpíadas do ano 2000; porém, com sua cadeira cor-de-rosa, Becky não cabia no carro da Barbie, no avião da Barbie e não podia subir para os andares superiores da "Casa dos Sonhos da Barbie", pois esta não tinha acessibilidade (LORD, 2004). Becky não estava incluída na rica vida de sua amiga.

A primeira coleção de bonecas exclusivamente negras lançadas pela Mattel, a Barbie So in Style, foi lançada em 2009. A designer Stacey McBride-Irby tinha como objetivo produzir bonecas mais fiéis aos tipos físicos e culturais da comunidade negra americana; porém, observa-se que as roupas, os acessórios, a fisionomia e os costumes das duas bonecas são os mesmos, diferindo apenas na cor do plástico do qual são fabricadas (STONE, 2010). Dessa forma, as bonecas negras não significam a democratização dos brinquedos ou uma problematização da diversidade, mas uma ampliação do mercado de bonecas, que procura atingir um número maior de meninas consumidoras.

O sucesso da boneca Barbie e sua permanência no mercado se devem também a representação de diferentes raças e etnias. As amigas da Barbie mostram que a emergência de bonecas negras não advém de uma preocupação em respeitar a diversidade, mas da expansão das vendas proporcionadas por essas novas bonecas. Reforçam a supremacia das características hegemônicas, uma vez que seus corpos plásticos são apenas pintados de negro. As representações das características fenotípicas permanecem as mesmas: longos cabelos lisos, nariz fino, lábios e cor dos olhos (SCHWARZ, 2006; TERRENÈE, 2008). A boneca loira continua sendo o padrão de beleza na qual as outras são fabricadas, ou seja, a Barbie governa sobre os outros modelos de bonecas.

Os estudos sobre governo, na perspectiva foucaultiana, preocupam-se em analisar os procedimentos, as táticas e as estratégias usadas para exercer o controle da conduta (FOUCAULT, 1993). Governamento "não se trata de impor uma lei aos homens, mas de dispor as coisas, isto é, utilizar mais táticas que leis, ou utilizar ao máximo as leis como táticas" (FOUCAULT, 1993, p. 284). É 
preciso dispor de meios e estratégias que levem a consecução de certas finalidades para bem governar. Diversos aparatos e procedimentos são dispostos para garantir a produção de certos efeitos. Assim, governamentalidade é um conjunto de procedimentos, análises, reflexões, cálculos e táticas. Ela é composta por uma conjunção de forças, arranjos técnicos e instrumentos que possibilitam a efetivação de programas de governo que têm por finalidade regular as ações individuais e coletivas (BUJES, 2002).

O traço distintivo do poder é que alguns homens possam mais ou menos integralmente determinar a conduta de outros homens - ainda que não de maneira exaustiva ou coercitiva [...] O governo dos homens pelos homens formem eles grupos modestos ou importantes, quer se trate do poder dos homens sobre as mulheres, dos adultos sobre as crianças, de alguma classe sobre a outra, ou de uma burocracia sobre uma população - supõe uma determinada forma de racionalidade e não uma violência instrumental [...] a questão é [então]: como são racionalizadas as relações de poder? (FOUCAULT, 1996, p, 64-65).

A produção de Foucault, na etapa final de sua vida, volta-se para o enlace entre as dimensões ética e política que operam na constituição do sujeito. O filósofo traça uma genealogia da subjetivação, distanciando-se das metanarrativas, que veem uma natureza biológica e psicológica determinante na constituição subjetiva. Foucault aponta o caráter histórico do "dispositivo da sexualidade", criado para a expansão do biopoder. A incitação a falar sobre sexo esteve intimamente associada a uma preocupação com o bem-estar das populações. Através desse dispositivo, o sexo tornou-se personalizado e medicalizado e deu origem a uma série de saberes específicos que se dedicaram a normatizar, estudar e controlar as condutas sexuais. Tal dispositivo exemplifica os modos de produzir verdades, o exercício do poder e a subjetivação do sujeito.

Para o controle das condutas individuais, uma série de tecnologias do eu são criadas e disseminadas, através de aparatos pedagógicos e táticas de poder das pessoas com elas mesmas. Essas técnicas englobam autovigilância, autoavaliação, confissão ou autonarração, que produzem efeitos na constituição das subjetividades. As tecnologias do eu se valem de discursos, tramas de linguagem, narrativas que visam produzir um tipo específico de sujeito. Essa genealogia da subjetivação mostra os diferentes modos de relação do sujeito consigo, partindo do conhecer-se a si mesmo até o cuidado com a saúde e o corpo. O autogoverno diz respeito aos modos de os indivíduos conduzirem-se a si mesmos, envolvendo alguma forma de controle e direcionamento ou modelo apresentado por diversos mecanismos políticos (FOUCAULT, 1993). Tal conceito torna possível a análise dos discursos das autoridades sociais e midiáticas que procuram operar sobre a vida dos indivíduos. Dessa forma, desloca-se o foco de análise: do poder do Estado para as múltiplas estratégias de controle da conduta presentes na cultura. 
As linhas de subjetividade são responsáveis pela produção pedagógica do sujeito por si mesmo. São linhas que buscam posicionar os sujeitos não como objetos silenciosos, mas como sujeitos falantes que devem contribuir ativamente para produção de si (LARROSA, 1995). A relação consigo por essas linhas adquire uma certa independência do poder, pois se torna "um poder que se exerce sobre si mesmo dentro do poder que se exerce sobre os outros" (DELEUZE, 1991). A relação consigo não pertence mais à ordem objetiva e enunciável, mas uma operação do sujeito sobre si mesmo. Dessa forma, as linhas de subjetividade permitem ao sujeito a possibilidade de criação de espaços onde é possível transgredir.

As subjetividades são formadas em um processo contínuo, fluído e inventado no transcurso de complexas histórias e vivências imbuídas de sentimentos de pertença, constituídos no interior de jogos de poder. As múltiplas subjetividades apresentadas pelos artefatos culturais, entre eles os brinquedos, produzem efeitos na constituição dos infantis (DORNELLES, 2003). Os bonecos e bonecas podem parecer, a princípio, objetos inocentes destinados às crianças. Contudo, estão imersos nas relações de poder, apresentando discursos implícitos à sua materialidade do que é bom, agradável, normal e verdadeiro para a cultura hegemônica. As bonecas apresentam muito da cultura hegemônica e do padrão de beleza eurocêntrico: pele branca, cabelos claros e lisos, corpo magro e olhos claros, o que ensina a supremacia de um corpo, raça e modo de ser.

Ao eleger uma estética corporal, uma raça, um gênero ou geração como "a melhor" se naturaliza e generaliza apenas um modo de subjetivação, e tudo o que é diferente se torna negativo. Isso ocorre também com a produção de bonecas, que não devem estar fora da norma vigente. Para Dornelles (2003):

\begin{abstract}
Algumas materialidades se sobrepõem a outras, produzindo certas 'normalidades', desse modo, é 'natural', no caso do uso de bonecos e bonecas, que os mesmos ao fazerem parte da sala de aula de crianças pequenas sejam da raça branca, com olhos azuis e longos cabelos loiros... Assim, tudo o que escapa ou se apresenta diferente deste 'modelo de normalidade', desta 'verdade' acerca da raça branca, é o 'diferente', o 'outro'. E este é o tipo de brinquedo consumido em série para crianças no que tange às 'diferenças' sejam elas raciais, de gênero, geração ou etnia. (DORNELLES, 2003, p.4).
\end{abstract}

Tendo em vista que as bonecas são objetos de identificação e representação da normalidade, elas retratam uma determinada época e lugar, através de marcas sociais que estão imersas em relações de poder. Tais marcas revestem-se de ricos significados culturais do ideal de beleza, de corpo e de sujeito. Ao elencar determinadas características como "as melhores", os corpos das bonecas fabricam modos de subjetivação que produzem "verdades" sobre como deve ser o corpo, o comportamento e as atitudes normais. 


\section{Conclusão}

Neste artigo, buscou-se argumentar como o "dispositivo" organiza-se, produz e incita o aprendizado de um conjunto de saberes e modelos comportamentais. Procurou-se mostrar como esse "dispositivo" promove linhas de subjetivação de modo que os infantis sejam convidados a falar de si e estabelecer uma relação reflexiva consigo mesmo através das brincadeiras com bonecas. As linhas de subjetividade tecem estratégias pelas quais as crianças podem efetuar um processo de objetivação de si mesmas, através das brincadeiras com as bonecas.

A Barbie cumpre um papel educativo. Envolta em um mundo de beleza, riqueza e aventura, que supostamente valoriza a diversidade e as diferenças, Barbie está imersa em uma pedagogia cultural, com o intuito de ensinar a supremacia de um tipo de corpo, raça e comportamento, além da produção de subjetividades infantis. A pedagogia analisada da boneca mostra que a pressão da publicidade impressa e difundida através de diferentes artefatos incorpora valores e modelos que são ubíquos na sociedade atual. O marketing por trás das Barbies étnicas, que pretendem representar minorias da sociedade, reforça as representações estereotipadas e a exclusão de determinados grupos. A Barbie personifica a fantasia de um mundo glamoroso, um ideal de beleza feminino, branco, magro e loiro.

\section{REFERÊNCIAS}

AUGUSTYNIAK, M. Barbie Doll Photo Álbum: 1959 to 2009 identification e values. Collector Books, 2010.

BROUGÈRE, G. Brinquedos e Companhia. São Paulo: Cortez, 2004.

BUJES, M. I. Infâncias e Maquinarias. Rio de Janeiro: DP\&A, 2002.

CONNEL, R. W. Masculinities. California II, 2005.

DEBOUZY, M. La poupée Barbie. Clio. N. 4. Disponível em: <http://clio.revues. org/index446.html>. Acesso : 10/02/2011.

DELEUZE, G. Foucault. São Paulo: Brasiliense, 1991.

DORNELlES, L. V.. O brinquedo e a Produção do Sujeito Infantil. Centro de Documentação e Informação sobre a Criança. Universidade do Minho. Instituto de Estudos da Criança. 2003. Disponível em: <http://cedic.iec.uminho.pt/Textos de_Trabalho/textos/obrinquedo.pdf> Acesso em: 03 de dez. de 2010.

FOUCAULT, M. A Ordem do Discurso. São Paulo: Loyola, 1996.

FOUCAULT, M. Microfisica do Poder. Rio de Janeiro: Graal, 1993. 
FOUCAULT, M. O uso dos Prazeres. In: História da sexualidade. V. 2. Rio de Janeiro: Graal, 1998.

FOUCAULT, M. Resumo dos cursos do Collège de France (1970-1982). Rio de Janeiro: Jorge Zahar, 1999.

GERBER. Barbie e Ruth: a história da mulher que criou a boneca mais famosa do mundo e fundou a maior empresa de brinquedos do século XX. São Paulo: Ediouro, 2009.

LARROSA, J. La experiência de la lectura. Barcelona: Laertes, 1996.

LORD, M. G. Forever Barbie: The unauthorized biography of a real doll. New York: Walker \& Company, 2004.

MITCHELL, C.A. REID-WALSH, J. Girl Culture: An Encyclopedia. Greenwood Publishing Group, 2007.

NIETSZCHE, F. Assim Falava Zaratustra: um livro para todos e para ninguém. Petrópolis: Vozes, 2011.

RAND, E. Barbie’s queer accessories. Durham: Ducke University Press, 2003.

ROVERI, F. T. Barbie - Tudo o que você quer ser... ou considerações sobre a educação de meninas. Dissertação de Mestrado. Universidade Estadual de Campinas, Faculdade de Educação, 2008.

ROGERS, M. F. Barbie culture. London: Sage Publications, 1999.

SCHWARZ, M. T. Native American Barbie: The Marketing of Euro-American Desires. American Studies, 46:3/4 (Fall-Winter 2005): 295-326. Disponível em: $<$ https://journals.ku.edu/index.php/amerstud/article/view/2964/2923>. Acesso: 20/07/2011.

SILVA, T. T. Documentos de Identidade: uma introdução às teorias do currículo. Belo Horizonte: Autêntica, 2007.

STONE, T. L. The Good, The Bad and The Barbie: a doll's history and her impact on US. New York: Viking, 2010.

STEINBERG, S. R. A mimada que tem tudo. In: STEINBERG, S. R. KINCHELOE, J. L. Cultura Infantil: a construção corporativa da infância. Rio de Janeiro: Civilização Brasileira, 2004. P. 321-338. 
TERRENÉE, R. Fulla, the veiled Barbie: An analysis of cultural imperialism and agency. MAI Review, 2008, 2, Santa Cruz Report. Disponível em: <http:// review.mai.ac.nz/index.php/MR/article/viewFile/132/151>. Acesso: 16/07/2011.

ZEGAI, M. Les jouets pour enfants au regard du genre. (Memoire de Master) - Departement de Sociologie, UFR Des Sciences Sociales et des Humsnites, Universite de Versailles-Saint-Quentin, Versailles, 2007.

Recebido em: 07 de abril de 2012

Aceito em: 10 de outubro de 2012 